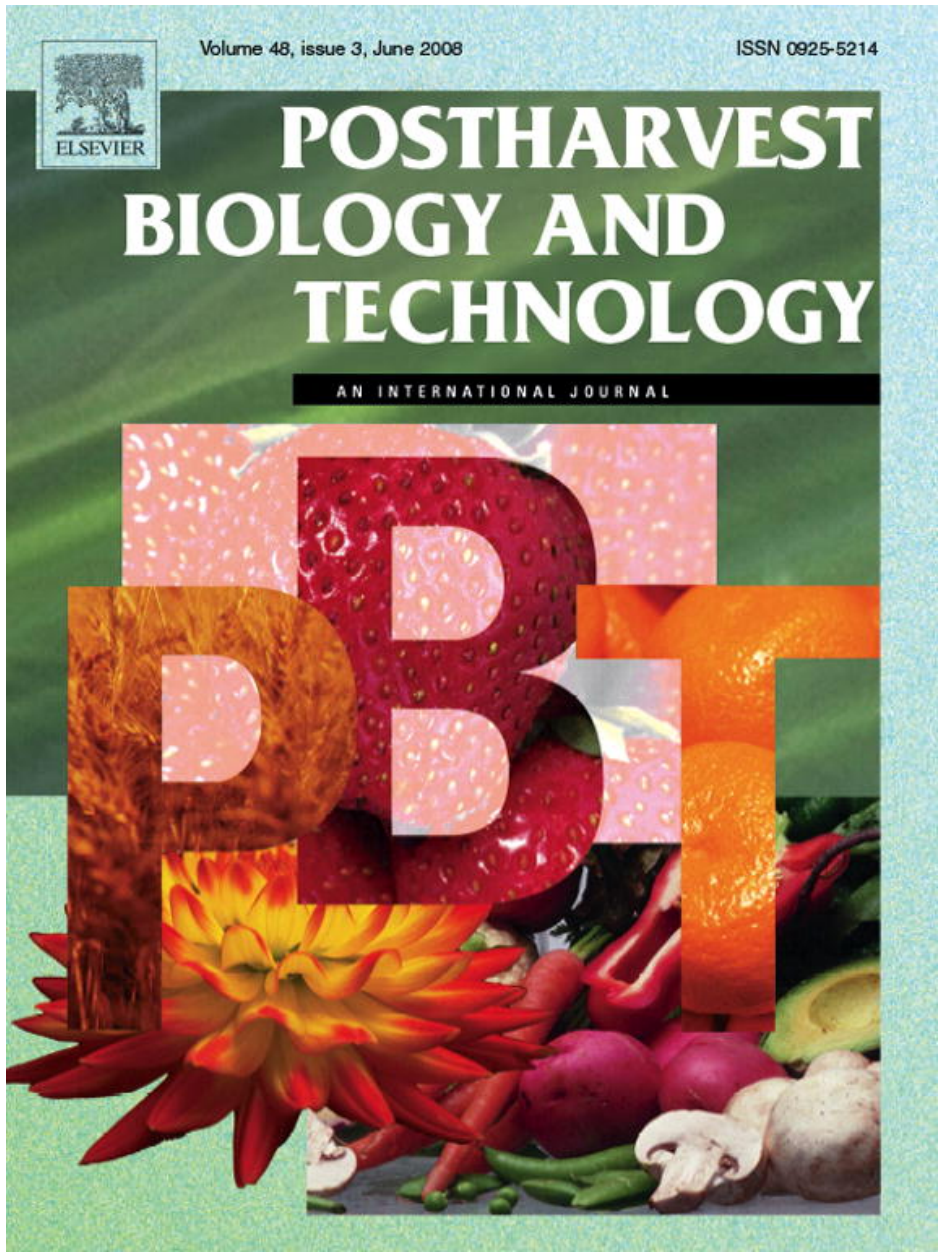

This article was published in an Elsevier journal. The attached copy

is furnished to the author for non-commercial research and education use, including for instruction at the author's institution, sharing with colleagues and providing to institution administration.

Other uses, including reproduction and distribution, or selling or licensing copies, or posting to personal, institutional or third party websites are prohibited.

In most cases authors are permitted to post their version of the article (e.g. in Word or Tex form) to their personal website or institutional repository. Authors requiring further information regarding Elsevier's archiving and manuscript policies are encouraged to visit: 


\title{
Avocado lenticel damage: The cause and the effect on fruit quality
}

\author{
Kerry R. Everett ${ }^{\mathrm{a}, *}$, Ian C. Hallett ${ }^{\mathrm{a}}$, Jonathan Rees-George ${ }^{\mathrm{a}}$, \\ Robert W. Chynoweth ${ }^{\mathrm{a}}$, Henry A. Pak ${ }^{\mathrm{b}}$ \\ ${ }^{a}$ The Horticulture and Food Research Institute of New Zealand, HortResearch Mt. Albert, Private Bag 92169, \\ Auckland Mail Centre, Auckland 1142, New Zealand \\ ${ }^{\mathrm{b}}$ The Avocado Industry Council Ltd., P.O. Box 16004, Bethlehem, Tauranga, New Zealand \\ Received 1 February 2007; accepted 1 September 2007
}

\begin{abstract}
Avocado fruit can develop small, 1-5 mm diameter brown spots immediately after harvest. These symptoms are typically more severe among fruit harvested following rain. The incidence of the brown spots increased significantly when fruit were artificially imbibed with water, but not when immersed in water. Morphological examination with the light and electron microscope showed there was a change in lenticels that was caused by water uptake. In unaffected fruit, large intercellular spaces were observed in cells below the lenticels, but when the fruit had taken up water, these cells became turgid and filled these spaces. Swollen cells associated with lenticels were more distended than other cells in the mesocarp, because the expansion of mesocarp cells was limited by adjacent cells. Swollen cells in the lenticels became brown more rapidly than other cells, probably because their turgidity made them more susceptible than other cells. Cells close to the surface were also more susceptible to discoloration than internal fruit cells. They were not prone to compression from adjacent cells towards the surface and were consequently more distended than internal cells. At harvest, prior to coolstorage, no fungal mycelium or spores were observed associated with lenticel damage symptoms. Surface-sterilised samples of lenticel damaged tissue failed to yield a fungal pathogen. In coolstorage, however, these fruit developed slightly sunken dark brown patches with irregular margins, referred to as measles, about $10-50 \mathrm{~mm}$ diameter The fungi Colletotrichum acutatum and Phomopsis sp. were isolated from such tissue in greater quantities than adjacent green tissue. Imbibation had no effect on measles development, but fruit jostled in a plastic crate to simulate damage that occurs at harvest developed more severe measles than fruit that were not damaged. There was no evidence that lenticel damage lead to measles but both symptoms were worsened by jostling.
\end{abstract}

(c) 2007 Elsevier B.V. All rights reserved.

Keywords: Avocado; Lenticel damage; Measles; Colletotrichum acutatum; Phomopsis

\section{Introduction}

Over $98 \%$ of avocados (Persea americana Mill.) grown for commercial use in New Zealand are of the Guatamelan $\times$ Mexican variety 'Hass'. 'Hass' is particularly suited to the relatively cool temperatures of New Zealand, and average yields of 4-10 tonnes per hectare are common. Fruit of the 'Hass' variety is green on the trees and immediately after harvest, but when it ripens following removal from the tree, the external colour changes to dark brown.

The exocarp of the avocado fruit consists of a single-layered epidermis covered by a thin waxy cuticle and a hypodermis of 1-3 cell layers with several underlying layers of parenchyma

\footnotetext{
* Corresponding author. Tel.: +64 98154200; fax: +64 98154201

E-mail address: KEverett@hortresearch.co.nz (K.R. Everett).
}

cells, and an interrupted layer of sclerenchyma tissue. Stomata are prominent in young fruit but may degenerate in older fruit due to the formation of lenticels (Scora et al., 2002). Mature fruit are covered with rind nodules, and lenticels randomly cover the surface of the fruit, with a greater concentration on the shorter side and toward the apex (Cummings and Schroeder, 1942). During harvest and packing, mechanical injuries can cause two types of damage symptoms: abrasions on the apex of protruding nodules, and lenticel damage. Nodule abrasions become covered by pale brown corky tissue but are not of concern because there is no further development of this injury during storage and ripening, and severely affected fruit can be easily detected and discarded before sale. Lenticel damage is typically apparent immediately after harvest and packing as small dark spots about $1-5 \mathrm{~mm}$ diameter (Fig. 1) and is more severe when fruit are harvested wet (Duvenhage, 1993). The aetiology of lenticel damage is not known. 

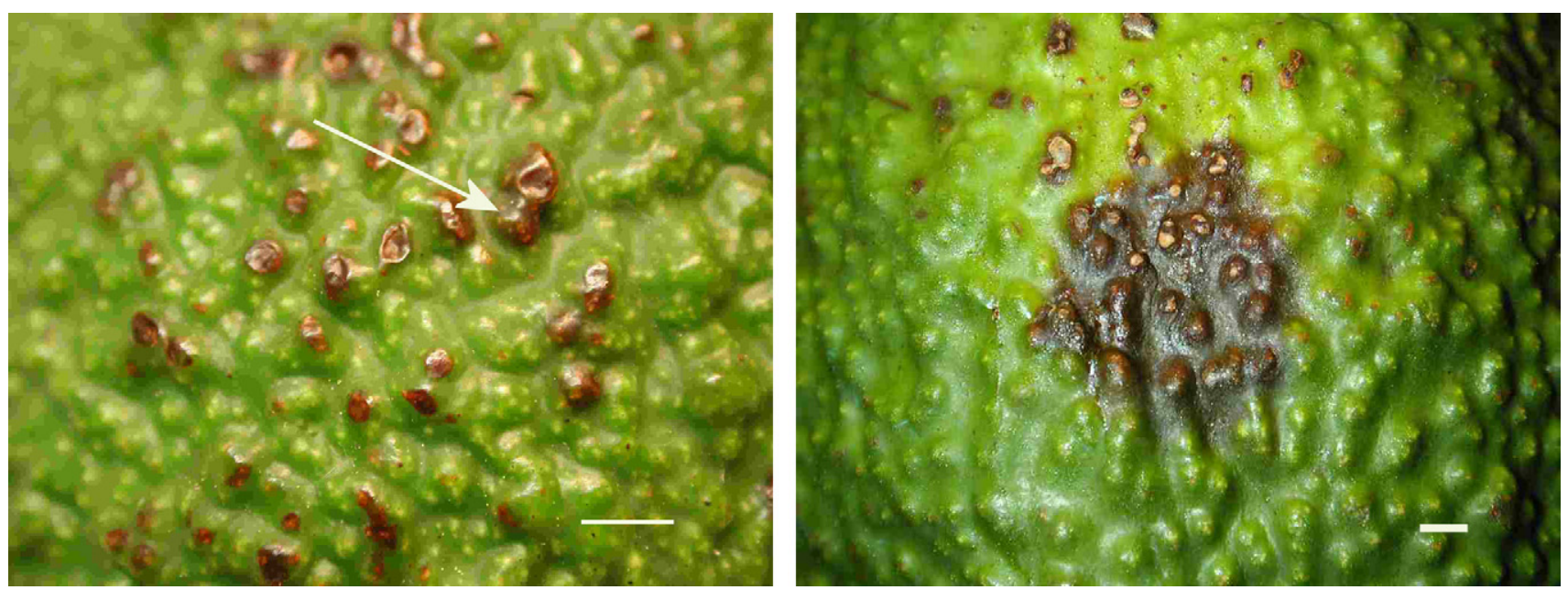

Fig. 1. Symptoms of lenticel damage on unripe 'Hass' avocado fruit after $24 \mathrm{~h}$ at $5.5^{\circ} \mathrm{C}$. Arrow shows area of diffuse browning characteristic of lenticel damage (left). Measles lesion after 45 days of coolstorage (right). Bar is $5 \mathrm{~mm}$.

Lenticel damage is of concern because of the adverse effect on fruit appearance upon arrival in the marketplace, and possible secondary infection leading to fruit rots in green fruit, referred to as measles. Measles symptoms are typically mid- to dark-brown blotches with regular or irregular margins that develop during coolstorage (Fig. 1). Lesions are approximately 1-5 cm diameter, and are similar to lesions described by Zamora-Magdaleno et al. (2001) caused by Colletotrichum gloeosporioides Penz. In more severe cases, measles lesions can become covered with orange-coloured fungal spores.

Mechanical damage to 'Hass' avocado fruit during packing has been studied by a number of workers (Timm and Brown, 1991; Hofman and Jobin-Décor, 1999; Baryeh, 2000), and microscopic studies of damage caused by friction and by $C$. gloeosporioides have been described (Zamora-Magdaleno et al., 2001). The differences in symptoms caused by insects on avocado fruit and mechanical damage have also been determined (du Toit et al., 1979). In mango a similar symptom has been attributed to host defence mechanisms induced by stress (Du Plooy et al., 2006). However, little is known about the anatomical changes to the avocado lenticel after damage or rain, or the role of fungal pathogens in lenticel damage. This work examines the cause of lenticel damage and its relationship with measles using several on-tree and detached-fruit treatments and by microscopical examination.

\section{Materials and methods}

\subsection{Fruit harvest}

All experiments were conducted in August and September 2000 (10-11 months after fruit set, 24\% dry matter). 'Hass' avocado fruit were carefully hand harvested in dry weather from orchards in the Patomahoe or the Orere Pt. districts $\left(37^{\prime} 2^{\prime \prime} \mathrm{S}\right.$ long.) $\sim 100 \mathrm{~km}$ south of Auckland and placed in plastic bins (50 fruit per bin). Fruit was transported to the laboratory at Mt. Albert Research Centre and arrived within $2 \mathrm{~h}$ after harvest. Fruit were treated immediately after arrival. For imbibing experiments, fruit were cut with a long $(\sim 25 \mathrm{~cm})$ peduncle attached.

\subsection{Water loss and uptake}

Fruit were treated on the tree (treatments 1 and 2), postharvest (treatments 3 and 4), and there was an untreated control (treatment 5). Fruit on trees were: (1) covered with polyethylene bags filled with $\sim 500 \mathrm{~mL}$ water to ensure that fruit were immersed; (2) covered with polyethylene bags for $24 \mathrm{~h}$ before harvest. At the same time, fruit with long peduncles were harvested and recut peduncles were inserted in an Erlenmyer flask almost completely filled with a weighed amount of reverse osmosis water (ROW). The opening of the flasks was covered with two layers of parafilm in which a small incision was made through which the peduncle was inserted. Fruit in flasks were placed on shelves in an enclosed chamber in a constant air flow generated by a row of fans at the rear, and a leaky closure at the front, in a constant temperature room $\left(20^{\circ} \mathrm{C}\right)$. Fruit in flasks were covered with a loosely fitting polyethylene bag (3) or not (4). (5) Controls consisted of harvested fruit with no further treatment. Fruit were treated for $24 \mathrm{~h}$ (treatments 1-4), harvested or removed from the airflow chamber, then damaged by rolling from one end of a $55 \mathrm{~cm}$ long plastic fruit bin to the other 10 times to simulate harvesting damage. This method of damaging fruit is subsequently termed jostling. Lenticel damage was recorded after fruit had been in the coolstore $\left(5.5^{\circ} \mathrm{C}\right)$ for $24 \mathrm{~h}$. For morphological studies fruit were jostled 50-60 times to minimise the time taken to find damaged lenticels by microscopy.

Fruit were subjected to treatment 3 to determine the time that was required for fruit to become more susceptible to lenticel damage. After commencement of water uptake, fruit were jostled after 5, 10, 15, $30 \mathrm{~min}, 1,2,4,8$ and $24 \mathrm{~h}$ and placed in a coolstore $\left(5.5^{\circ} \mathrm{C}\right)$ After $24 \mathrm{~h}$ further fruit were removed from the water source and placed in the airstream to simulate drying out after rain. Fruit were removed 5, 10, 15, 30 min, 1, 2, 4, 8 or $24 \mathrm{~h}$ after commencement of dehydration, jostled and placed in a coolstore $\left(5.5^{\circ} \mathrm{C}\right)$. Fruit were removed and symptoms were 
assessed $24 \mathrm{~h}$ after final placement of fruit in the coolstore. These experiments were conducted several times for varying times of drying and imbibing.

\subsection{Relationship of lenticel damage with measles}

Fruit were: (1) imbibed for $24 \mathrm{~h}$ (treatment 3) above; (2) imbibed and damaged by jostling; (3) not imbibed and (4) not imbibed and damaged. Lenticel damage was counted $24 \mathrm{~h}$ after fruit were placed in the coolstore, and measles were assessed as a percentage of coverage of the fruit $22 \mathrm{~d}$ after being placed in the coolstore.

In a second experiment, fruit were: (1) damaged and (2) not damaged. Fruit were placed in the coolstore and assessed for lenticel damage after $24 \mathrm{~h}$ and for measles after $22 \mathrm{~d}$.

\subsection{Fungal isolations}

Isolations were made aseptically from symptoms of lenticel damage measle symptoms and from adjacent spots on the surface of the avocado fruit, following wiping with $70 \%$ ethanol and placing excised spots on potato-dextrose-agar (PDA) medium in Petri plates. Fungi were identified by spore and culture morphology after growth for $2-3$ weeks at $\sim 20^{\circ} \mathrm{C}$ under fluorescent lights (12-h light:12-h dark cycle).

\subsection{Microscopic observations}

Freshly harvested fruit were examined after the following treatments: (1) not imbibed; (2) imbibed with water for 5-24 h; (3) imbibed for 5-24 h then dehydrated for 5-8 h. Fruit were chosen for examination that contained numerous lenticels, identified by pale yellow spots on the green skin. After each of the above three treatments, fruit were jostled 50-60 times. Representative samples containing lenticels were taken from all treatments before jostling, and from treatments (1) and (3) immediately after jostling. For treatment (2), areas of brown patches associated with lenticels appeared and these were sampled at intervals between 15 and $30 \mathrm{~min}$ and $2 \mathrm{~h}$ after jostling, and at $24 \mathrm{~h}$ after jostling. In all cases, portions of the skin and underlying flesh were excised. These samples were then either observed immediately in a fresh state, or fixed, or frozen.

Samples of fresh unfixed fruit were cut using a vibrating blade microtome (Vibratome 1000, Technical Products International, St. Louis, MO, USA) to give $50 \mu \mathrm{m}$ or $100 \mu \mathrm{m}$ thick sections.

Material for embedding was fixed in FAA (3.7\% formaldehyde, $5 \%$ acetic acid, 50\% ethanol), dehydrated in an ethanol series and wax embedded. Sections were cut at 10 or $15 \mu \mathrm{m}$ and mounted on glass slides. Sections were de-waxed in xylene and stained using safranine/fast green for histology or magdala red/light green to detect hyphae.

All observations were conducted on a Vanox AHT light microscope (Olympus Optical, Tokyo) and images recorded using a CoolSnap digital camera system (Roper Scientific, AZ, USA).

Material for scanning electron microscopy was attached to copper stubs using tissue freezing medium (Triangle Biomedical
Sciences, Durham, NC, USA) and frozen in liquid nitrogen. Samples were stored in liquid nitrogen until observation. For surface observation, samples were transferred under dry argon/nitrogen to the transfer device of an Emscope SP 2000 Sputter Cryo system. The stub was then transferred under vacuum to the preparation chamber where excess surface ice was sublimed away under vacuum at a temperature of $-80^{\circ} \mathrm{C}$. The sample was then sputter coated with gold at a temperature of lower than $-150{ }^{\circ} \mathrm{C}$ and transferred under vacuum to the specimen chamber of a Philips PSEM505 scanning electron microscope where it was held on a cold stage at a temperature of less than $-150{ }^{\circ} \mathrm{C}$. Observation was carried out at an accelerating voltage of $12 \mathrm{kV}$. For observation of internal structures, the tissue was freeze fractured in the preparation chamber prior to sublimation. Subsequent processing was the same as for non-freeze fractured samples.

\subsection{Data analysis}

Data were analysed using the GLM, ANOVA and CORRELATION functions of MINITAB version 12 (Minitab Inc., USA). Means were separated using Tukey's test at $P<0.05$. For imbibation experiments, three-way analysis of variance was carried out using imbibation, damage and fruit as factors. Data were displayed using the graphics package ORIGIN (Microcal Software Inc., USA).

\section{Results}

\subsection{Water loss and uptake}

\subsubsection{Effect of water immersion on fruit before harvest and detached fruit}

Jostled fruit that were detached and imbibed whilst covered with a polyethylene bag had significantly $(P<0.01)$ more damaged lenticels than untreated control fruit. No other treatment resulted in significant increases in numbers of damaged lenticels (Table 1).

\subsubsection{Water uptake, drying and susceptibility to lenticel damage}

After $2 \mathrm{~h}$ of water uptake, the number of lesions caused by jostling significantly $(P<0.05)$ increased (Fig. 2). Although not significant, lesion number increased after 4 and $8 \mathrm{~h}$, and at $24 \mathrm{~h}$ the increase was again significant $(P<0.05)$. When before and after $2 \mathrm{~h}$ were compared, there was a significant increase in lesion number after this time $(P<0.05)$.

When fruit was taken out of the water and placed in the air stream, the fruit became significantly less susceptible to damage after $2 \mathrm{~h}$ dehydration (Fig. 2). There was more variation in the response of individual fruit to water loss than to water uptake, and thus the change in susceptibility was not as obviously delimited as in imbibed fruit. However, after $8 \mathrm{~h}$, the mean number of lesions induced by jostling had decreased to 6-12, compared with 20-25 lesions in imbibed fruit. Differences were statistically different $(P<0.01)$ after 2 and $8 \mathrm{~h}$. 
Table 1

Number of damaged lenticels following jostling and placing in the coolstore for 2 days

\begin{tabular}{llllll}
\hline & \multicolumn{2}{l}{ Treatment } & Control \\
\cline { 2 - 5 } & \multicolumn{2}{l}{ Attached to tree } & \multicolumn{2}{l}{ Detached from tree } & \\
\hline Imbibed & - & - & + & + & - \\
Water in bag & + & - & - & - & - \\
Bagged & + & + & + & - & - \\
Mean & 37.8 & 35.8 & 47.4 & 41.0 & 32.2 \\
S.E.M. & 2.14 & 2.40 & 4.27 & 3.13 & 2.82 \\
Number of fruit & 18 & 20 & 20 & 15 & 15 \\
$P$ value & $\mathrm{ns}$ & $\mathrm{ns}$ & 0.002 & $\mathrm{~ns}$ & \\
\hline
\end{tabular}

Fruit were treated on the tree (attached) or were removed with a long peduncle (detached). Fruit attached to the tree were covered with a plastic bag with or without water (water in bag and bagged, respectively) for $24 \mathrm{~h}$ before they were harvested. Detached fruit were imbibed by placing the cut peduncle in water in an airflow chamber for $24 \mathrm{~h}$ with or without a plastic bag covering the fruit (bagged or not). After these treatments fruit were jostled by rolling from one end of a plastic bin to the other 10 times and placed in the coolstore at $5.5^{\circ} \mathrm{C} . P$ value is from Tukey's test comparing treatment and control.

\subsection{Relationship of lenticel damage to measles}

Both lenticel damage and measles were significantly related to damage $(P<0.0001$ and $P=0.016$, respectively, Table 2$)$. Only lenticel damage was significantly related to imbibation $(P=0.047)$. When lenticel damage and subsequent measles development in the same fruit after 22 days coolstorage were compared using the linear regression function of ORIGIN, there was a weak linear relationship $(R=0.47, P<0.0001$, $n=80$ ). If only damaged fruit were included in the comparison, the relationship remained significant $(R=0.42, P=0.008$, $n=39$ ).

\subsection{Fungal isolations}

A range of saprotrophic fungi and bacteria (three isolations of Bacillus sp., one of Cryptosporiopsis sp., four of Cladosporium sp., one of Botryosphaeria sp., two of mycelia sterilia and six samples from which no organisms were obtained) were isolated from 17 areas of diffuse browning associated with lenticel damage. Isolations from measles symptoms that had been allowed to develop in the coolstore showed that Colletotrichum acutatum Simmonds ex Simmonds and Phomopsis spp. were the fungi isolated most commonly from measles compared with symptomless regions on fruit that had been kept in coolstorage (Table 3).

\subsection{Microscopic observations}

Lenticels in 'Hass' avocado fruit were marked by small pale yellow spots ( $\sim 0.3 \mathrm{~mm}$ diameter) on the green skin. When the surface was viewed using the scanning electron microscope the only evidence of the lenticel was a small elliptical pore with a maximum diameter of $20 \mu \mathrm{m}$ (Fig. 3). Occasionally the surface wax, or cuticle, appeared to be absent from the cells immediately surrounding the pore. Internally the pore lead to a cavity of

Table 2

The effect of imbibation and jostling on lenticel damage and measles

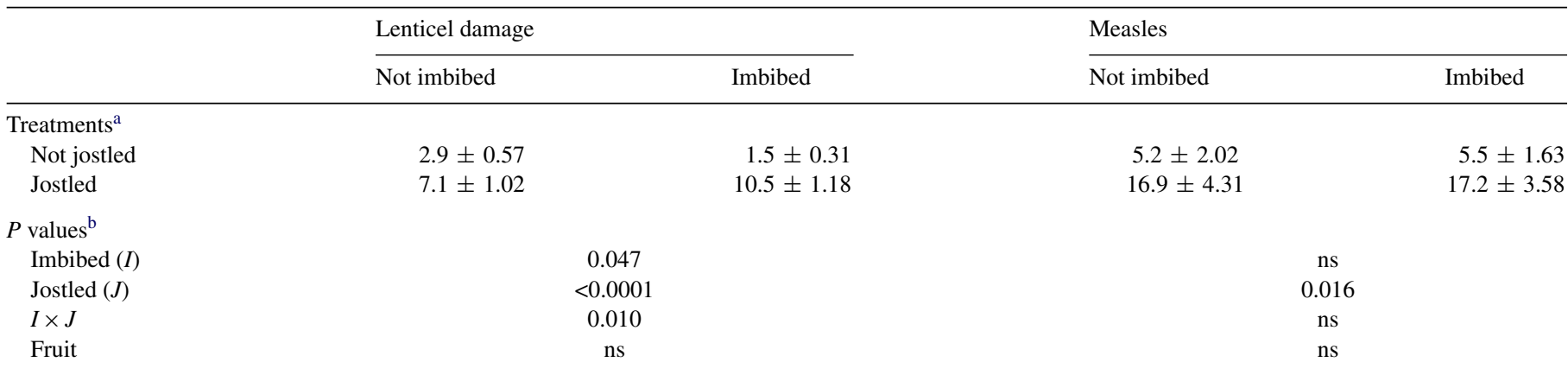

Fruit were harvested with a long peduncle that was inserted in water in an airflow chamber (imbibed) or not (not imbibed). After $24 \mathrm{~h}$ fruit were removed and jostled by rolling from one end of a plastic bin to the other 10 times. Fruit were then placed in the coolstore $\left(5.5^{\circ} \mathrm{C}\right)$, lenticel damage was assessed after $24 \mathrm{~h}$ and measles was assessed after 22 days.

a Values are means \pm S.E.M. for 40 fruit.

b $P$ values are from a three-way analysis of variance.

Table 3

Isolations from 100 fruit that had been jostled and placed in the coolstore for 4-5 weeks until measles symptoms developed

\begin{tabular}{|c|c|c|c|c|c|c|c|c|}
\hline & \multicolumn{5}{|c|}{ Fungi isolated } & \multirow[t]{2}{*}{ No isolation } & \multirow[t]{2}{*}{ Mycelia sterilia } & \multirow[t]{2}{*}{ Total } \\
\hline & C.a. ${ }^{a}$ & C.g. & B.p. & B.d. & P. & & & \\
\hline Symptomless & 6 & 24 & 2 & 0 & 0 & 163 & 5 & 200 \\
\hline Measles & 50 & 20 & 4 & 0 & 29 & 85 & 12 & 200 \\
\hline
\end{tabular}

Four samples of skin swabbed with 70\% ethanol were taken from each fruit, two from measles symptoms and two from symptomless regions (control).

${ }^{a}$ C.a., Colletotrichum acutatum; C.g., Colletotrichum gloeosporioides; B.p., Botryosphaeria parva; B.d., Botryosphaeria dothidea; P., Phomopsis. 

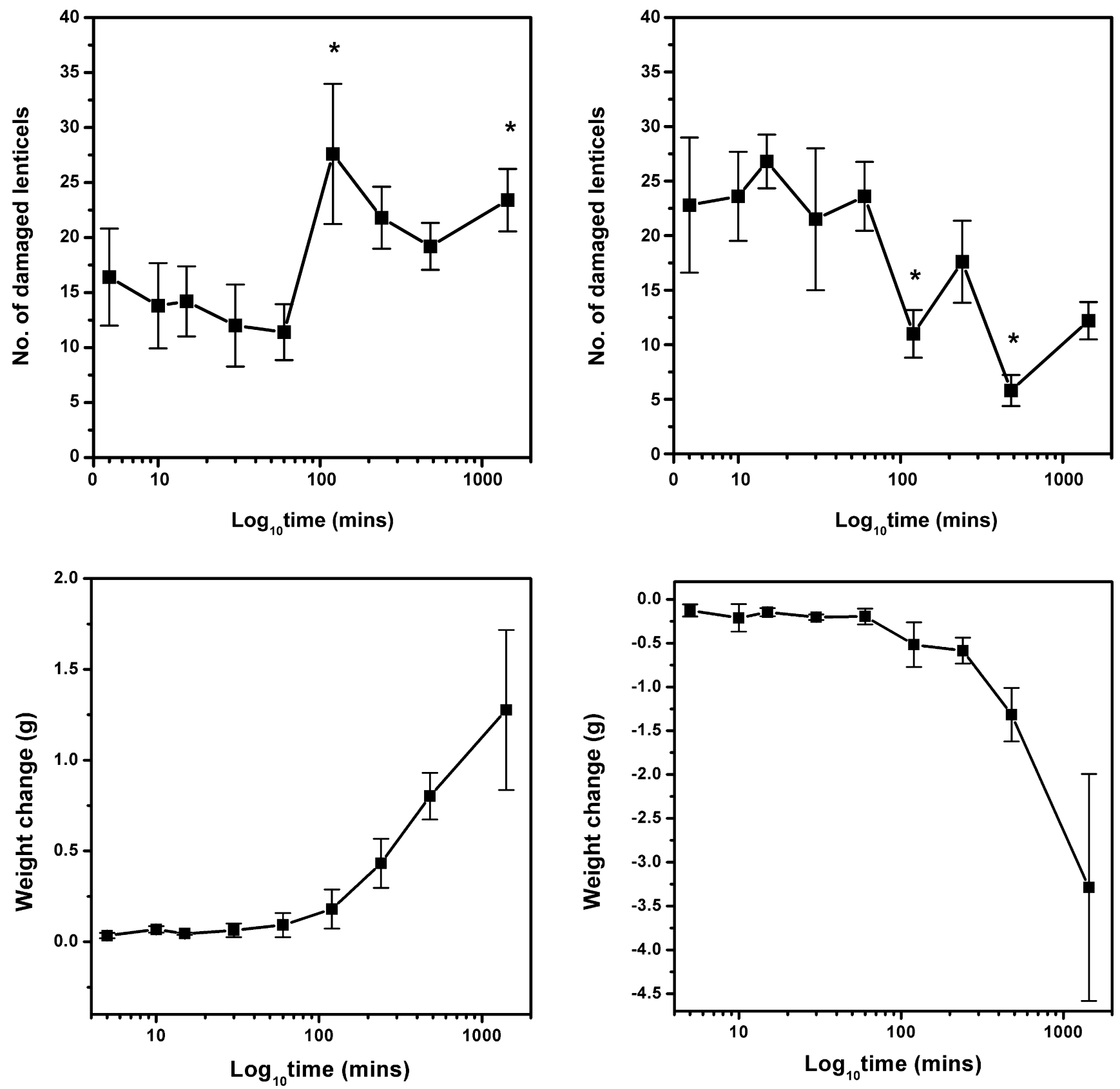

Fig. 2. Effect of water imbibation (left) and dehydration (right) on susceptibility to lenticel damage. Upper graphs indicate numbers of damaged lenticels after jostling and $24 \mathrm{~h}$ at $5.5^{\circ} \mathrm{C}$. Lower graphs indicate water uptake as fruit are imbibed by placing stems in water and covering with a plastic bag in a constant airflow chamber and water loss when fruit were removed from bags and water and placed in the constant airflow chamber. Water loss and gain were measured by weight change in fruit. Asterisk (*) indicates significant difference according to Tukey's test $(P<0.05)$ to number of damaged lenticels after 5 min treatment. Values are means \pm S.E.M. of three replicate fruit.

variable size surrounded by and containing loosely packed cells. These differed markedly in the density of their packing and content from that of normal sub-epidermal cells. These cells also contained few plastids (Fig. 4). The pore leading into the cavity was similar to an inactive stoma.

As fruit take up water the loosely packed cells within the lenticellular region expanded and became rounded (Fig. 4). Eventually they occupied the whole sub-epidermal space. Following drying of the fruit the cells contracted and the subepidermal cavity was recovered.
Diffuse browning appeared as a mid to deep brown discolouration usually up to only a few millimetres in diameter. Observation of the surface using scanning electron microscopy revealed no apparent differences compared with that of nondiscoloured portions of the fruit. In cross-sections, a distinct browning could be seen in the flesh below the epidermis (Fig. 5). The epidermis and one or more cell layers below frequently showed no apparent damage, whilst below this a large area of cells did show browning, internal disruption, and some cell wall damage. Occasionally the epidermis and immediate 

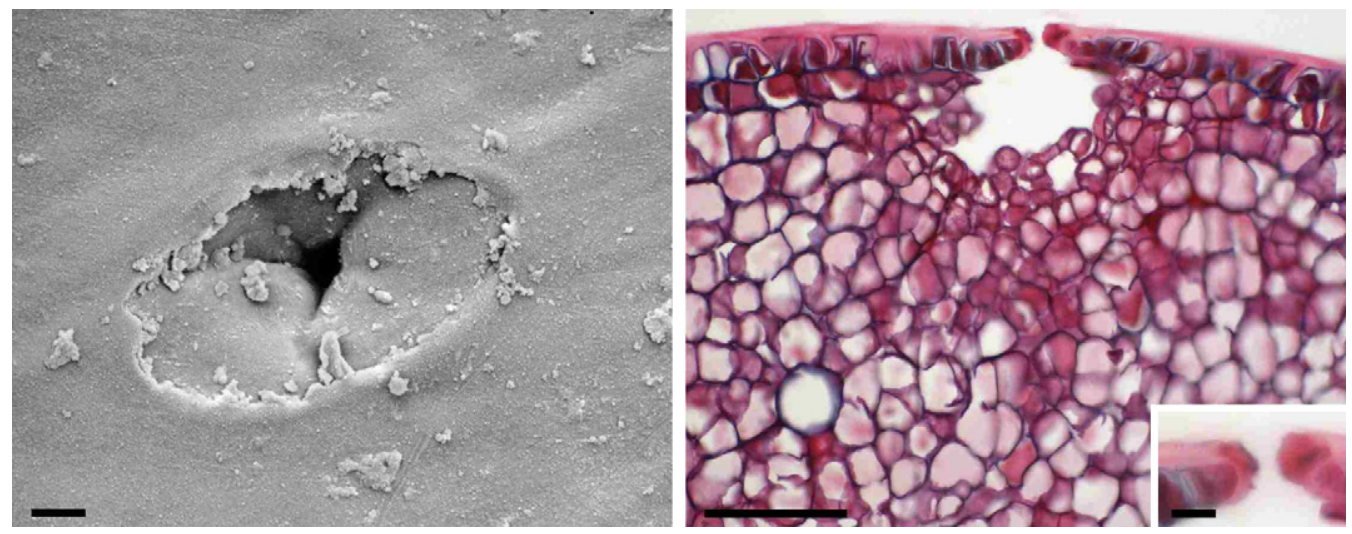

Fig. 3. Surface of avocado fruit showing a lenticel pore with part of the cuticular layer absent by low temperature scanning electron microscopy. Bar $=10 \mu \mathrm{m}$ (left). Cross-section of lenticel from fixed tissue. Pore is clearly visible and is detailed in the inset. Cells similar to stomatal guard cells are adjacent to the pore. The tissue was fixed in FAA, embedded in wax and stained with safranin/fast green. Bar $=0.1 \mathrm{~mm}$ and $10 \mu \mathrm{m}$ for inset (right).

sub-epidermal cell layers themselves showed similar browning (Fig. 5). In the region of lenticels the browning always extended to the surface and considerable cellular damage could frequently be seen.

Jostling water-imbibed fruit to simulate grading/handling damage always resulted in the occurrence of diffuse browning. This could be seen $30 \mathrm{~min}$ after rolling as slightly discoloured areas of the skin. At this stage, microscope observations showed patchy areas of browning in the flesh, and much of the browning appeared to be the result of diffuse pigmentation. More extensive browning and discernible cellular collapse were visible in the region of the lenticels (Fig. 5). After $2 \mathrm{~h}$, more extensive browning could be seen. Discoloration and cellular damage was intense around lenticels and extended to the surface. Large areas of discoloration also occurred in cell layers under the epidermis and immediate sub-epidermal layers (Fig. 5). After $24 \mathrm{~h}$,
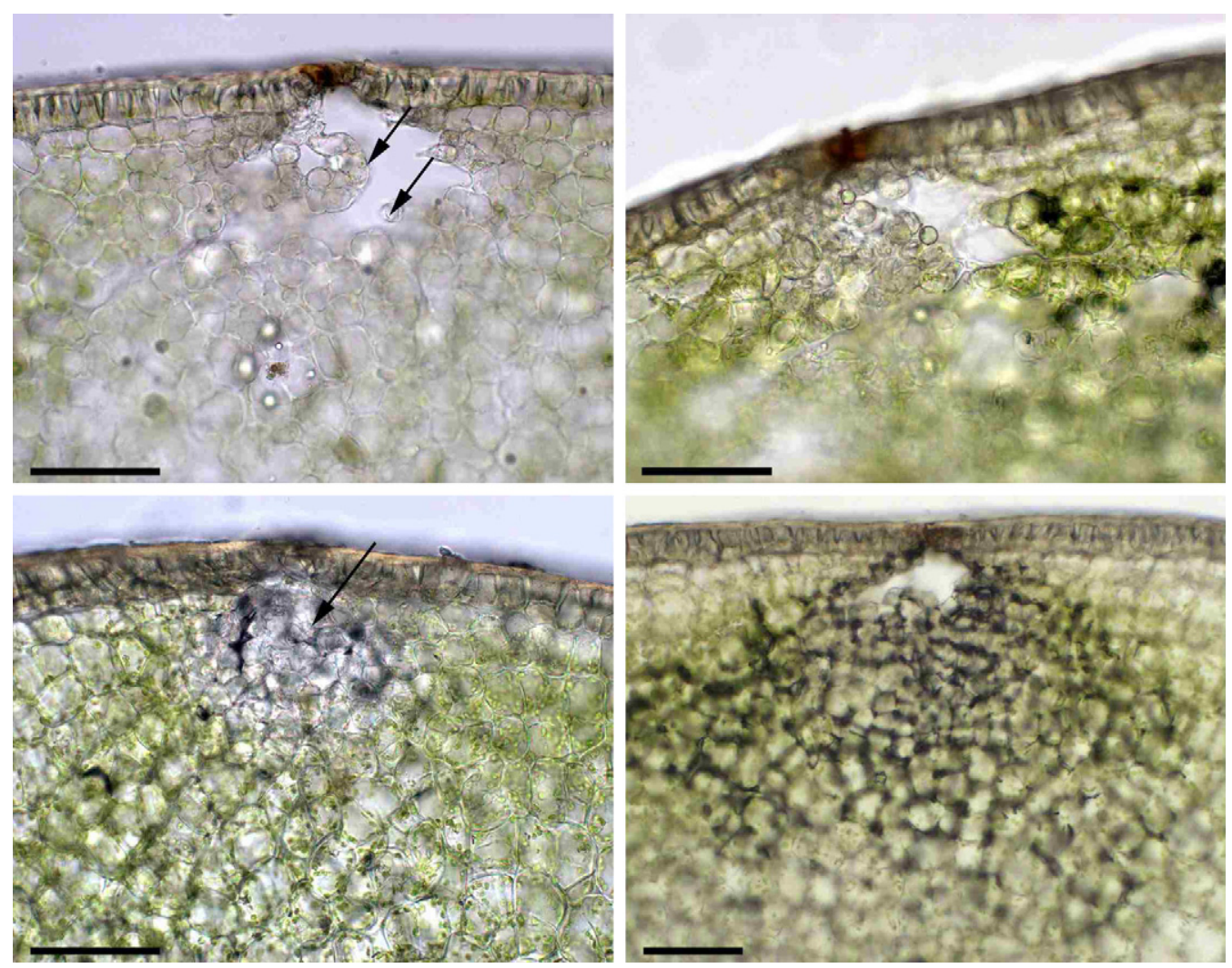

Fig. 4. Cross-section of lenticel from untreated fruit with distinct cavity showing loosely packed cells (arrow). These cells contain few plastids compared with adjacent skin cells (top left). Lenticel from fruit after $4 \mathrm{~h}$ of imbibing water. Lenticel cavity is reduced in size and loosely packed cells have started to round (top right). Swollen rounded loosely packed cells occluding the cavity (arrowed) after $12 \mathrm{~h}$ of imbibing water. These have few chloroplasts resulting in the region below the lenticel pore remaining a less intense green than other parts of the skin (bottom left). Lenticel cavity has re-formed in fruit imbibed then allowed to dry (bottom right). The tissue was unstained vibrotome sections examined under the light microscope. Bars $=0.1 \mathrm{~mm}$. 

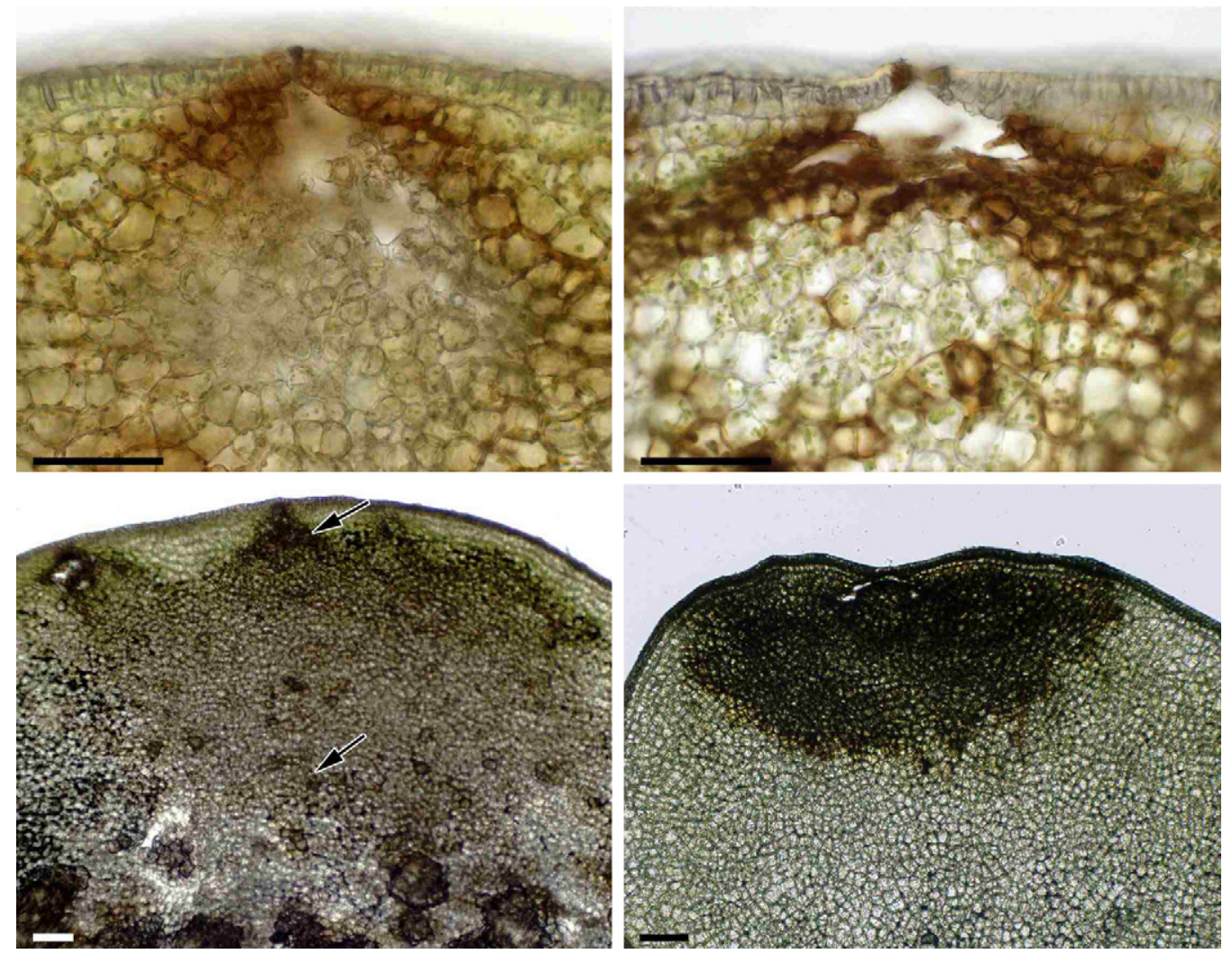

Fig. 5. Browning in areas adjacent to the lenticel $2 \mathrm{~h}$ after treatment (top left). More extensive browning extending to sub-epidermal cells adjacent to the lenticel $8 \mathrm{~h}$ after treatment (top right). Browning extending out from the lenticel area $30 \mathrm{~min}$ after treatment (bottom left). More extensive browning originating at the lenticel, $24 \mathrm{~h}$ after treatment (bottom right). Bars $=0.1 \mathrm{~mm}$.

large areas of diffuse browning had developed. No fungal hyphae or structures were observed in or adjacent to damaged lenticel cells.

\section{Discussion}

Our results suggested that fruit became more susceptible to lenticel damage after approximately $2 \mathrm{~h}$ of imbibing water, hydrated fruit became less susceptible to lenticel damage after approximately $2 \mathrm{~h}$ of losing water, and skin cells in hydrated fruit became more turgid and more susceptible to damage. This is in general agreement with another study of avocado lenticel damage (Duvenhage, 1993) in which it was shown that lenticel damage was significantly greater in fruit picked wet compared with dry. In a similar study on harvesting damage to potato tubers, it was found that tubers were more easily injured when water saturation was increased and intercellular spaces were less (Weber, 1990).

Lenticels in avocado appeared to be derived from stomata, the pore being delimited by non-functional guard cells and a sub-stomatal cavity lined by loosely packed cells which probably delimits the lighter area of skin visible on the fruit surface. These loosely packed cells differed in shape, cell density, and virtual absence of plastids from the normal skin parenchyma cells. There appeared to be little further differentiation of the lenticel structure, which presumably acts as a channel for water loss from the fruit.
In times of high water availability, it is likely that all cells of the fruit increase in water content. However, expansion of most cells within the fruit is limited by the dense cellular packing. The loosely packed cells around and in the lenticel are able to expand and fill the entire cavity. Because of the virtual absence of chloroplasts from these cells, this region is clear in section, and expansion of cells does not change the paler surface appearance of the lenticel region. The expansion of these cells appears to be completely reversible when the fruit is allowed to lose water.

It is likely that browning, which produces the areas of diffuse browning visible on the surface, results from the breakdown of cellular membranes caused by impact and compression forces on cells that have been stressed by increased turgor pressure. Membrane rupture may destroy compartmentalisation in the cells and result in the production of visible brown phenolic products. It is likely that the greater effect seen in the lenticel regions is due to greater fragility of these cells because they are less constrained by adjacent cells and are able to expand to a greater extent, increasing internal stress. In contrast, when the force is transmitted deeper into the tissue the cells are less distended and less damage occurs. In non-imbibed tissue where diffuse browning is less frequent, the less turgid cells are more easily able to absorb the forces without damage.

Isolations from lenticels showing diffuse browning failed to yield pathogenic fungi, but saprotrophic fungi were found. Microscopical examination failed to detect fungal structures in lenticel damaged tissue. In contrast, the fungi C. acutatum and 
Phomopsis spp. were associated with measles symptoms. These results show that the cause of lenticel damage is not fungal, whilst measles is probably related to fungal invasion. Thus, the two disorders have different causes.

The cause of a symptom similar to measles in Mexican 'Hass' fruit was C. gloeosporioides (Zamora-Magdaleno et al., 2001), a fungus closely related to $C$. acutatum but with a lesser tolerance to cold temperatures (Everett, 2003). The higher frequency of $C$. acutatum suggests that this fungus has become the more common pathogen in the cooler temperatures of New Zealand avocado orchards. The other fungi usually associated with avocado postharvest rots (Hartill, 1991) were either not or rarely isolated (Botryosphaeria dothidea (Moug. Ex Fr.) Ces. \& de Not. and Botryosphaeria parva Pennycook \& Samuels), or isolated in equal numbers from apparently symptomless tissue $(C$. gloeosporioides).

It is possible that saprophytic fungi invade damaged lenticel tissue, and then fungal pathogens invade to cause measles, but no direct evidence was found for this hypothesis. Instead, mechanical damage increased the incidence of both measles and lenticel damage. Lenticel damage symptoms were weakly correlated with measles that developed in the same fruit. Instead of being a causal relationship it is possible that as both were worsened by injury then both symptom types were related to mechanical damage rather than to each other.

Further work is required to investigate the relationship between lenticel damage and measles. If the two symptoms are unrelated, then lenticel damage is of aesthetic importance only, because symptoms are only visible in unripe fruit. When 'Hass' avocado fruit darken as they become ripe, the general browning obscures symptoms of lenticel damage, and the problem could be managed by selling lenticel-damaged fruit when ripe. From the evidence presented here, it seems that harvesting fruit that are not imbibed with water and treating fruit as gently as possible after harvest will ameliorate both symptom types.

\section{Acknowledgements}

Many thanks to David Billings, Dr. Nagin Lallu, Dr. Jem Burdon (HortResearch) for use of the high airflow chamber and Dr. Jonathan Dixon (NZ Avocado Industry Council) for valuable discussion; Graham Coles, Dave Turner and Brian Bell (Avocado growers) and Dr. Ross Ferguson (HortResearch) for fruit and to Tracy Olsen and Lisa Benson for technical assistance. Also thanks to the NZ Avocado Industry Council for funding.

\section{References}

Baryeh, E.A., 2000. Strength properties of avocado pear. J. Agric. Eng. Res. 6 , 389-397.

Cummings, K., Schroeder, C.A., 1942. Anatomy of the avocado fruit. Calif. Avo. Soc. Yearbook, vol. 27, pp. 56-64.

Du Plooy, G.W., Van der Merwe, C.F., Korsten, L., 2006. Lenticel discolouration in mango (Mangifera indica L.) fruit-a cytological study of mesophyll cells from affected tissue. J. Hort. Sci. Biotech. 81, 869-873.

du Toit, W.J., de Villiers, E.A., Tuffin, A., 1979. The identification of causes of typical surface lesions on avocado fruit. SAAGA Res. Report 3, pp. 52-53.

Duvenhage, J.A., 1993. The influence of wet picking on post harvest diseases and disorders of avocado fruit. SAAGA Yearbook, vol. 16, pp. 77-79.

Everett, K.R., 2003. The effect of low temperatures on Colletotrichum acutatum and Colletotrichum gloeosporioides causing body rots of avocados in New Zealand. Aust. Plant Path. 32, 441-448.

Hartill, W.F.T., 1991. Post-harvest diseases of avocado fruits in New Zealand. N. Z. J. Crop Hort. Sci. 19, 297-304.

Hofman, P.J., Jobin-Décor, M., 1999. Effect of fruit sampling and handling procedures on the percentage dry matter, fruit mass, ripening and skin colour of 'Hass' avocado. J. Hort. Sci. Biotech. 74, 277-282.

Scora, R.W., Wolstenholme, B.N., Lavi, U., 2002. Taxonomy and botany. In: Whiley, A., Schaffer, B., Wolstenholme, B. (Eds.), The Avocado: Botany, Production and Uses. CABI Publishing, Wallingford, UK, pp. 15-37.

Timm, E.J., Brown, G.K., 1991. Impacts recorded on avocado, papaya and pineapple packing lines. Appl. Eng. Agric. 7, 418-422.

Weber, J., 1990. Intercellular spaces enhance potato tuber elasticity. Potato Res. 33, 335-340.

Zamora-Magdaleno, T., Cardenas-Soriano, E., Cajuste-Bontemps, J.F., ColinasLeon, M.T., 2001. Anatomy of damage by friction and by Colletotrichum gloeosporioides Penz. in avocado fruit 'Hass'. Agrociencia 35, 237-244. 